\title{
NEUROTRANSMITTER AND BRAIN PARTS INVOLVED IN SCHIZOPHRENIA
}

\author{
ASHWANI ARYA ${ }^{1}$, GULSHAN SINDHWANI ${ }^{1 *}$, RENU KADIAN $^{2}$
}

${ }^{1}$ Department of Pharmaceutical Education and Research, BPS Women University, South Campus, Bhainswal Kalan, Sonipat - 124 001, Haryana, India. ${ }^{2}$ Department of Pharmacy, Faculty of Pharmaceutical Sciences, PDM University, Bahadurgarh - 124 507, Haryana, India. Email: sindhwani.gulshan@gmail.com

Received: 01 January 2018, Revised and Accepted: 20 February 2018

\begin{abstract}
Schizophrenia (SCZ) is a major debilitating, complex, and costly illness that strikes $1 \%$ of the world's population. It is characterized by three general types of symptoms: Atypical symptoms (aggressiveness, agitation, delusions, hallucinations), depressive symptoms (alogia, avolition, anhedonia, apathy), and cognitive symptoms (impaired attention, learning, memory). The etiology of SCZ has still not been fully understood. Alteration in various neurochemical systems such as dopamine, serotonin, norepinephrine, gamma-aminobutyric acid, and glutamate are involved in the pathophysiology of SCZ. The lack of understanding regarding the exact pathogenic process may be the likely a reason for the non-availability of effective treatment, which can prevent onset and progression of the SCZ. The tools of modern neuroscience, drawing from neuroanatomy, neurophysiology, brain imaging, and psychopharmacology, promise to provide a host of new insights into the etiology and treatment of SCZ. In this review, we will discuss the role of the various neurotransmitter concerned and brain parts exaggerated in the SCZ.
\end{abstract}

Keywords: Schizophrenia, Memory, Cognitive dysfunction, Dopamine, Glutamate.

(C) 2018 The Authors. Published by Innovare Academic Sciences Pvt Ltd. This is an open access article under the CC BY license (http://creativecommons. org/licenses/by/4. 0/) DOI: http://dx.doi.org/10.22159/ajpcr.2018.v11i6.24557

\section{INTRODUCTION}

Schizophrenia (SCZ) is categorized by a spectrum of symptoms that characteristically consist of chaotic thinking, societal withdrawal, hallucinations (both acoustic and optical), delusions of persecution (suspicion), and peculiar manners. These symptoms are sometimes considered as "positive" (such as hallucinations) and "negative" (such as communal departure and lethargy). SCZ is a common and devastating disease which is categorized by chronic psychotic symptoms and psychosocial destruction [1]. An understanding of the pathophysiology of SCZ will be important to the invention of an anticipatory method and healing intervention. Rapidly advancing research into SCZ includes diverse etiological hypothesis and offers instructions for prospect investigate and treatments [2].SCZ is a constant and distressing neuropsychiatric disorder affecting $1 \%$ of the world population. It is associated with disturbances in social performance and has high suicidal rates leading to personal and family suffering. In psychiatric disorders, improper alterations in cortical circuitry and synaptic transmission in the developing brain occurs due to primary alterations in the activity of these molecules, which could then translate into the neural dysfunction [3]

The onset of the disease occurs mainly in late adolescence and adulthood. There is certain evidence, which signifying the susceptible genes and environmental risk factors associated with the SCZ and how these interactions between them self-leading to the progression of disease. All these evidence have supported the fact that there are deficits during neurodevelopment that is the main root cause of the pathophysiology of the disease [4,5]. The risk factors operate synergistically with both neurodevelopment and glutamate-associated signaling [6]. The characteristic feature of the disease is intense and long-lasting impairments mainly in language, memory, and cognition, as well as the brain regions, subserving these domains are affected structurally and functionally [7]. It imposes an excessively large financial load in terms of hospitalization, chronic treatment, psychotherapy, and lost efficiency [8]. Males are more vulnerable to SCZ rather than females which start from mid to late adolescence through early adulthood [9]. During the premorbid stage of the disease, minor physical anomalies and subtle motor, societal, or cognitive impairments are often observed. However, these differences commonly fail to place persons outside the regular range of performance. Attenuated positive symptoms, mood symptoms, cognitive symptoms, societal withdrawal, or obsessive activities may arise in the prodromal stage $[10,11]$. It is a remarkable challenge for the scientific community represented by SCZ, which produces the human suffering, family tragedies, and financial burden [9]. Even though some insights into the etiology of SCZ have been developed, an indulgent of the disease on the molecular level remains indescribable. Thus, essential avenues characterized by neuroanatomy, neurophysiology, brain imaging, and psychopharmacology during modern investigation [10].

\section{CLINICAL FEATURES OF SCZ}

SCZ is a destructive ill health that strikes at some of the highly developed functions of the human brain. Psychotic or "positive" symptoms (aggressiveness, agitation, delusions, and hallucinations), deficit or "negative" symptoms (alogia, avolition, anhedonia, and apathy), and cognitive dysfunction (impaired attention, learning, and memory) are three main categories of symptoms. The psychotic symptoms of SCZ are a feature of many brain diseases but are often the most disturbing and noticeable symptom to others. Hallucinations, delusions, and thought disorder are three main categories included in psychotic symptoms. The rigorous disturbances in social relations, enthusiasm, expression of affect, ability to understanding enjoyment, and natural tongue considered under the negative symptoms [12,13]. Elite functions such as concentration, memory, and general cerebral performance are affected by cognitive disfigurement in SCZ. The psychotic symptoms have an episodic pattern, but the negative and cognitive symptoms are more persistent and chronic and when active is usually the impetus for hospitalization $[14,15]$.

During the first 5-10 years, both positive symptoms such as delusions, hallucinations, negative symptoms like impaired cognition, decision, sensation and deterioration of the substantial functions such as work, interpersonal relationships as usually occurs after the onset of full syndrome. Fuzzy disturbances in the form and content of thought, observation, cognition, feeling, sense of self, desire, social relationships, and psychomotor behavior which further defines SCZ characteristically [16]. 
- Symptoms of a acute episode may include the following: Being out of touch with actuality; hallucinations (particularly hearing voices); delusions (fixed false beliefs); ideas of influence (performance embarrassed by external influences); detached thought processes (wobbly relations); ambivalence (differing in belief); flat, improper, or labile influence: Autism (solitary and secretly directed opinion); lack of support, lack of sympathy, and orally or bodily violence: Impaired self-cured skill; and distressed sleep and hunger [13].

- The patient usually has remaining character (e.g., nervousness, suspiciousness, lack of desire, lack of enthusiasm, poor insight, impaired judgment, societal extraction, complexity in wisdom from understanding, and poor personality skills), after the acute psychotic episode [12]. The various clinical features of SCZ are summarized in Fig. 1 [12].

\section{Neurotransmitter hypothesis of SCZ}

There are a number of theories of SCZ, dominated for many years by neuropharmacology, that implicate aberrant neurotransmission systems, in particular, aberrant dopaminergic, serotoninergic, and glutamatergic systems. It is unclear; however, to what extent any neurochemical findings reflect primary rather than secondary pathology, compensatory mechanisms, or environmental influences $[15,23,24]$. Certain studies have suggested that dysregulation of dopaminergic, gamma-aminobutyric acid (GABA), glutamatergic neurotransmission, and their interactions are involved in the pathophysiology of SCZ [25-27]. Neurotransmitters and the pathogenesis of SCZ are summarized in Table 1.

\section{Dopaminergic hypothesis}

Psychoses may result from hyper- or hypoactivity of dopaminergic processes in specific brain regions. This may comprise the presence of a dopamine (DA) receptor defect. The dopaminergic hypothesis of SCZ considers that an improper dopaminergic transmission at the dopamine D2 receptor in the mesolimbic and prefrontal brain regions is responsible for schizophrenic symptoms mainly positive [24]. In spite of having several limitations until now, this hypothesis remains the prominent neurochemical theory. There is certain evidence such as dopamine presynaptic storage dysfunction, abnormal vascular transport, release, reuptake, and metabolic abnormality in the mesolimbic dopamine system, which suggests the involvement of presynaptic dopaminergic abnormality in the illness. Dysregulation and hyperresponsiveness of presynaptic dopamine neurons further induce oxidative stress which may lead to long-lasting consequences. As a result, dopamine activity may be decreased in the neocortex, responsible partially for negative symptoms such as emotional or cognitive impairment [11].

GABAergic inhibitory input that arises from the ventral pallidum is considered to be the most potent input to the dopaminergic neurons. Dopaminergic projections that are linked to SCZ which involved in the mesocortical system. This system arises in the ventral tegmental area (VTA) and projects to numerous cortical areas including mainly the prefrontal cortex, anterior cingulate cortex (ACC), and the temporal lobes. Abnormality in dopaminergic signaling, as well as the mesolimbic and nigrostriatal projections, is likely to be involved in SCZ [28].

The dopamine levels are found to be enhanced in the substantia nigra and the striatum of the basal ganglia, the levels found to be decreased in the cortex of schizophrenic patients. In neuroleptic-naive patients, changes in dopamine synthesis, storage, and release results in an overactive striatal dopaminergic system [29]. The high striatal dopamine function has been strongly linked to motor dysfunction and psychotic symptoms [30]. The D1 and D2 dopamine receptor abnormality, likely thought to be responsible for some of the abnormal behavioral and motor symptoms seen in SCZ [31].

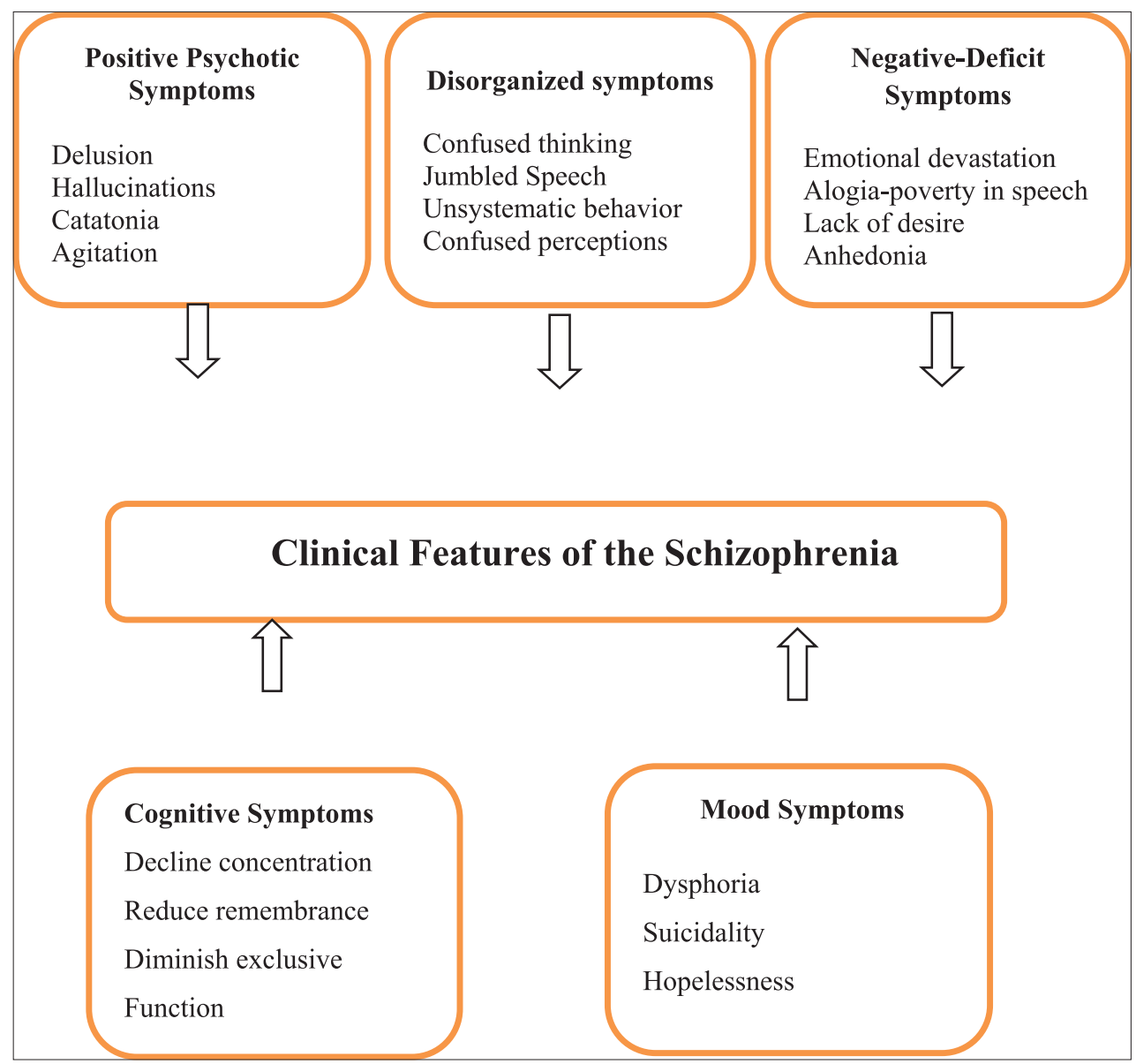

Fig. 1: Clinical features of schizophrenia 
Table 1: Neurotransmitters and the pathogenesis of SCZ

\begin{tabular}{|c|c|c|c|c|}
\hline Neurotransmitters & Action of NT & Brain part involved & Receptors & References \\
\hline Dopamine & Increase/decrease & $\begin{array}{l}\text { Mesolimbic (positive symptoms) and } \\
\text { mesocortical (negative symptom) }\end{array}$ & D2 and D4 & [17] \\
\hline Serotonin & Increased & Prefrontal cortex (negative symptoms) & 5-HT2A and 5-HT1A & {$[18,19]$} \\
\hline Glutamate & $\begin{array}{l}\text { Glutamate receptor binding } \\
\text { changes }\end{array}$ & Prefrontal cortex, thalamus, and hippocampus & NMDA & {$[20,21]$} \\
\hline GABA & Decrease & Limbic and prefrontal cortical & GABA A & {$[21,22]$} \\
\hline
\end{tabular}

GABA: Gamma-aminobutyric acid, NMDA: N-methyl-D-aspartate, SCZ: Schizophrenia

This hyperstimulation is thought to result from highly sensitive D2 receptors, antipsychotic drugs (amphetamine or methylphenidate) exacerbated psychotic symptoms in SCZ patients [32]. In the nigrostriatal projection, dopamine is produced and synthesized in the substantia nigra, in turn stimulating movement through D1 receptors. Dopamine by binding to the $\mathrm{D} 2$ receptors via the GABA neurons which inhibits the indirect pathway and suppresses movement [33].This indirect pathway begins with cortical excitation of the striatal neurons and excites the GABA neurons, discrete from those that are excited in the direct pathway. The neurons in the substantia nigra are projected and inhibit the motorrelated functions of the thalamus. The balance between two conjugate pathways is needed for normal motor function [34]. There are four main dopamine pathways in the brain. The mesolimbic system concerned with the addiction, emotion, perception \& pleasure and reward-seeking behaviors, cognition. The mesocortical pathway involved in attention, emotional behavior, learning, and memory. The nigrostriatal pathway implicated in movement and sensory stimuli and tubuloinfundibular pathway for the control of inhibition of the prolactin hormone secretions and functions of the hypothalamic-pituitary endocrine systems. The pathways of dopamine in brain and SCZ are summarized in the Fig. 2 [35].

The dopamine hypothesis of SCZ proposed that the positive symptoms of the illness arose as a consequence of the hyperactivity of the dopaminergic system, in the mesocortical and mesolimbic area of the brain whose origin lies in the VTA. The dopamine hypothesis has been made to reconcile by focusing on other neurotransmitters that may interact with dopamine in discrete cortical and subcortical neural circuits. Dopamine heteroreceptors have been suggested to regulate the release of glutamate in the striatum; this finding is an evidence for the hypothesis which suggests the involvement of abnormal levels of both glutamate and dopamine in the corticostriatal Pallidal thalamic circuit in the etiology of SCZ. Along with the dopamine-glutamate abnormality in the corticostriatal systems, the possible involvement of other subcortical regions has also accounted for schizophrenic symptoms. The important area of the brain involved in new memory formation, information processing, and generation of specimen-specific behaviors are hippocampus and entorhinal cortex. Morphological and cytoarchitecture abnormalities in these areas of the brain have been suggested for the positive symptoms of SCZ. Hippocampus and entorhinal cortex are innervated by the dopaminergic system, while glutamate is considered to be the predominant intrinsic excitatory neurotransmitter. Thus, the positive symptoms of the illness may be considered to be related to the hippocampus dopamine-glutamate system dysfunction [12].

\section{Brain-derived neurotrophic factor (BDNF)}

BDNF has been associated with the pathophysiology of SCZ. However, it is not clear whether alterations in BDNF observed in schizophrenic patients are a core part of disease neurobiology or a result of treatment. The neurotrophic factors, such as nerve growth factor, BDNF, neurotrophin-3 (NT-3), and neurotrophin-4/5 (NT4/5) support the development, differentiation, and survival of nerve cells during growth and are also involved in the maintenance and flexibility of adult neurons [36].

Dopamine (DA) has been strongly having a major role in the pathophysiology and management of SCZ. There are several studies, which show an interactions between BDNF and the DA system. In the cell cultures from embryonic rat and human ventral mesencephalon, BDNF reduces the loss of tyrosine hydroxylase and protects dopaminergic neurons from neurotoxic agents such as 6-hydroxydopamine and 1-methyl-4-phenylpyridinium [37]. It has been reported by several studies that there is a significant reduction in serum BDNF levels of chronic and medicated schizophrenic patients compared to healthy volunteers [38].

\section{Serotoninergic system}

Recent focus has been changed toward the involvement of serotonin (5-hydroxytryptamine, 5-HT) in the pathophysiology of SCZ [39]. Serotonin is an essential neurotransmitter synthesized from dietary tryptophan. The possible role of serotonin in SCZ was first recognized in the 1950's when serotonin was noticed to be similar to lysergic acid diethylamide (LSD). LSD competes for and occupies serotonin's receptor sites with very high potency, resulting in the development of psychosis-like symptoms. The hypothesis was supported by the fact that typical antipsychotics, when used in combination with a 5-HT2 antagonist such as ritanserin resulted in a considerable relief of patient's negative symptoms and motoric side effects. 5-HT2A receptor regulation appears essential for many of the features of the atypical antipsychotic drugs. All atypical antipsychotic drugs have been shown to have a favorable 5-HT2A/D2 affinity ratio in vitro and in vivo. The number of cortical 5-HT2A and 5-HT1A receptors is altered in schizophrenic brains [40]. 5-HT2C receptor antagonists are likely to produce weight gain and possibly seizures [18]. Certain polymorphisms of the 5-HT2A receptor gene are associated with SCZ; the trophic role of serotonin in neurodevelopment may be usurped in SCZ; 5-HT2A receptor-mediated activation of the prefrontal cortex may be impaired in some schizophrenics, and serotoninergic and dopaminergic systems are interdependent and may be simultaneously affected in SCZ [39]. Newer antipsychotic drugs are targeting serotonin receptors, and so the system is being studied for SCZ. Decreased in the cortical 5-HT2A receptor concentration and increased in the 5-HT1A receptor density have been reported in SCZ [41,42].

\section{Glutamatergic system}

Glutamate is the most abundant amino acid neurotransmitter in the mammalian brain. There are two types of glutamate receptors: Metabotropic and ionotropic receptors. The ionotropic receptors are subdivided into three subtypes and are the major focus in SCZ: $\mathrm{N}$-methyl-D-aspartate (NMDA), quisqualate/gamma-amino-3-hydroxy5-methyl-4-isoxazolepropionic acid (amino-3-hydroxy-5-methylisoxazole-4-propionic acid [AMPA]), and kainate [43]. However, the NMDA receptor (NMDAR) is the most studied and relevant receptor subtype to understand the pathophysiology of SCZ. The NMDA receptor plays an important role in neurocognition and toxicity [44]. The NMDAR D-serine/glycine site on the NR1 subunit is not fully saturated at synapses in brain regions such as the prefrontal cortex, neocortex, hippocampus, thalamus, and brainstem slices, suggesting that agonists of the D-serine/glycine site are capable of regulating NMDAR-mediated neurotransmission [45]. Glycine is a major inhibitory neurotransmitter throughout the brain. The synapses are extensively reorganized during postnatal brain development up to young adulthood. NMDA receptor also plays a key role in the major changes of reorganization of glutamatergic synapses [46]. NR2A and NR2B subunits have dissimilar conductance and calcium permeability. NR2A and NR2B subunits are highly expressed 


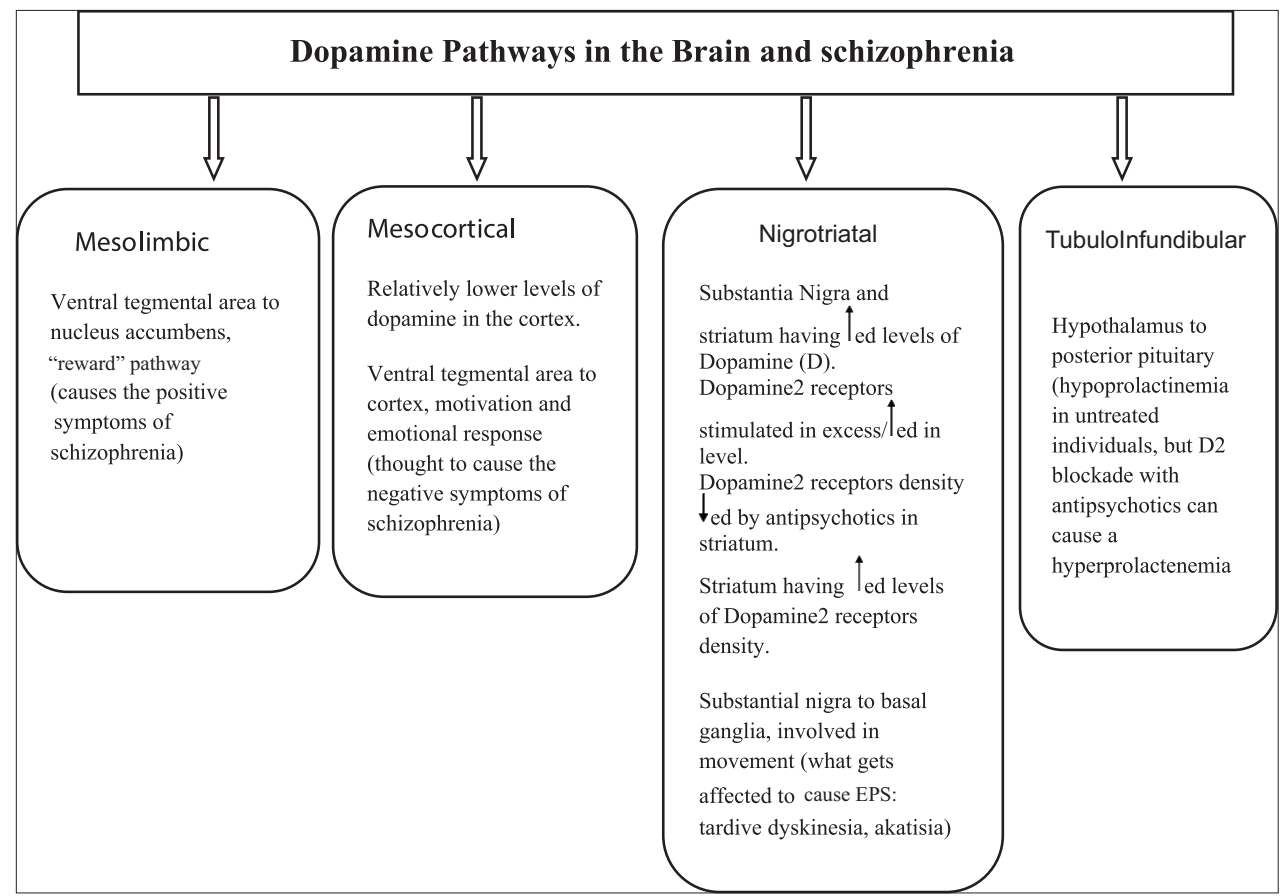

Fig. 2: Major pathways for the dopaminergic system in the brain and schizophrenia

in the forebrain corticolimbic regions and undergo a developmental shift: Switching progressively from richness in NR2B subunits in the early postnatal brain into richness in NR2A subunits during development [47]. A major role of this shift is to change the threshold for modifying synaptic power. Therefore, the ratio of NR2A/NR2B has a significant contribution in the development of cortical functions [48]. This developmental switch results in changes in brain plasticity and synaptic transmission [49]. One more important neurodevelopmental process is "synaptic pruning," in which synapses are reorganized into more competent configurations, including glutamatergic synapses. Much evidence suggests that hypofunction of NMDA receptor-mediated neurotransmission is a significant deficit in SCZ [50]. Effects on different symptom domains of SCZ such as negative symptoms, cognitive deficits, and quality of life, except neurotransmission, synaptic flexibility, memory, and cognition are also regulated by the NMDA receptor. Thus, reduction of NMDA receptor-mediated neurotransmission may result in loss of neuronal plasticity and cognitive deficits [51].

The dopaminergic and glutamatergic system of the brain are interconnected, and thus, inhibition of one system will influence the functioning of the other system [52]. The NMDA receptor antagonist diminishes the corticofugal inhibition of subcortical dopamine neurons and hence enhances dopaminergic transmission [53]. It was concluded by PET studies that acute administration of NMDA-receptor antagonists increases dopamine release in the striatum and chronic administration elicits decreased dopamine release or hypoactivity in the prefrontal cortex [54]. AMPA and kainate receptors are non-NMDA glutamate receptors that get overactivated by NMDA receptor. Glutamate release as a response to NMDA receptor antagonists might in part be responsible for their behavioral effects. NMDA receptor hypofunction may alter synaptic connectivity leading to abnormality $[35,55]$.

\section{NMDA}

Abnormality in the dopamine levels in schizophrenic brain remains highly pertinent to deficits in reward response, novelty detection, attention, and neuroplasticity [56,57]. Unusual dopamine signaling is a consequence of many other primary modulatory abnormalities, including NMDAR dysregulation [58]. Among relevant receptor systems, NMDARs have drawn maximum attention due to historical observations that the NMDAR antagonist phencyclidine produces a syndrome in healthy individuals which resembles SCZ. Electrophysiological findings provide additional support for a link between NMDA and GABA in SCZ, as reduced NMDAR depended on inhibitory drive results in the increased excitability that characterizes SCZ [59].

\section{Acetylcholine}

Neurotransmitter acetylcholine controls the activity of the cholinergic system in the central nervous system (CNS) and is important in many functions such as learning and memory [60]. Acetylcholine functions by activating two families of receptors, the nicotinic receptors which are ligand-gated ion channels and muscarinic receptors which a G-proteincoupled receptors [61]. There are five types of muscarinic (M1-M5) receptors and all are present in the human CNS but are expressed in a different way on CNS regions and different cells and capable of controling different CNS functions [62]. The belief that muscarinic receptors were involved in the pathophysiology of SCZ came from early clinical neuropsychopharmacological studies. It was the demonstration that in the caudate-putamen from patients with schizophrenia $(3 \mathrm{H})$ pirenzepine binding was less [63]. It was a good an effort in better understanding the role of muscarinic receptors in the pathophysiology of SCZ. The lower levels of $(3 \mathrm{H})$ pirenzepine binding were also reported in the cortex and hippocampus in schizophrenic patients. It is therefore significant that it is lower levels of muscarinic M1 receptor (CHRM1), that accounts for the decreased levels of $(3 \mathrm{H})$ pirenzepine binding in the cortex of patients with SCZ $[64,65]$.

\section{Cognitive and neurological abnormalities in SCZ}

SCZ is associated with defective memory, attention, executive, and intellectual impairment [66,67]. Yet, a gracious literature has emphasized that dysfunction in basic motor function and control represents an extremely pertinent physiological pathway in the disease [68]. The motor dysfunction in SCZ is more direct, showing the impairments in basic motor processing and control. Medial orbitofrontal cortex and rostral part of the ACC (rACC) were responsible for emotional processing and decision-making, as well as playing an important role in social behavior and interaction. It was supported by the evidence that the brain regions such as the dorsal ACC, the basal ganglia, and the cerebellum, which are associated with memory and executive control are implicated in SCZ $[69,70]$. 
There are several evidences which indicate that the brain's limbic system is involved in SCZ. In addition, the dopaminergic mesolimbic tract (originates in the VTA of the midbrain and projecting to a number of limbic regions) is considered to play a most important role in the development of positive psychotic symptoms of SCZ. The neuroleptic drugs show improvement of the psychotic symptoms by blocking D2 receptors in the limbic structures [71]. There is a reduction in volume of limbic structures in SCZ and histological abnormalities are seen in medial temporal lobe structures, that is, the hippocampal formation, amygdala, and adjacent cortical areas [72]. The gray matter volume decreases in medial temporal lobe and an increase of the temporal horn of the lateral ventricles [73]. There is an increase and decrease in metabolic activity in the medial temporal lobe regions of schizophrenics [74]. The abnormalities include a decrease in area or whole volume of the hippocampus as well as in the number of hippocampal neurons, reduced neuronal size and density, and pyramidal cell disarray, the majority of cases consistent with hippocampal sclerosis [75]. The various brain parts and its features are shown in Fig. 3 [76].

SCZ is a "thought disorder," and thinking has been conceptualized as an "active motor process." The basal ganglia are considered as cognitive and motor pattern generators [76]. It generates sequences of action which designs the future action. Schizophrenic patients with motor abnormalities predict deficits in memory, decision-making, and concentration [77]. The corticocerebellar inhibition of the motor cortex is important in the coordination of motor sequences, which has been suggested to be impaired in various findings. Thus, cerebellar organization influences the fidelity of perceptions, error detections, and quick modulation of coordination [78]. SCZ may impair these functions of cerebellum resulting in misinterpretation of incorrect sensory associations usually suppressed by the cerebellum, resulting in the repeatedly noted evidence of anomalous prophetic coding in the illness [79].

The basal ganglia play a role in sequencing the activation for fast actions by balancing movement and muscle activation [80]. Connections to the corticopontocerebellar system make the cerebellum which a main control area for voluntary motor control, enhances the structures relevance for SCZ [81]. The main output center of the cerebellum is the dentate nucleus, which links premotor, prefrontal, posterior parietal and primary motor cortex mainly through the thalamus. These areas of cortex sends back the projections for the processing through pons. These corticocerebellar loops link function of the cerebral cortex to the cerebellum and vice versa. The cerebellum is thought to act as a timer, updating and predicting body dynamics for fast movements based on sensory feedback, and this precision is assumed to have high temporal fidelity [82-84].

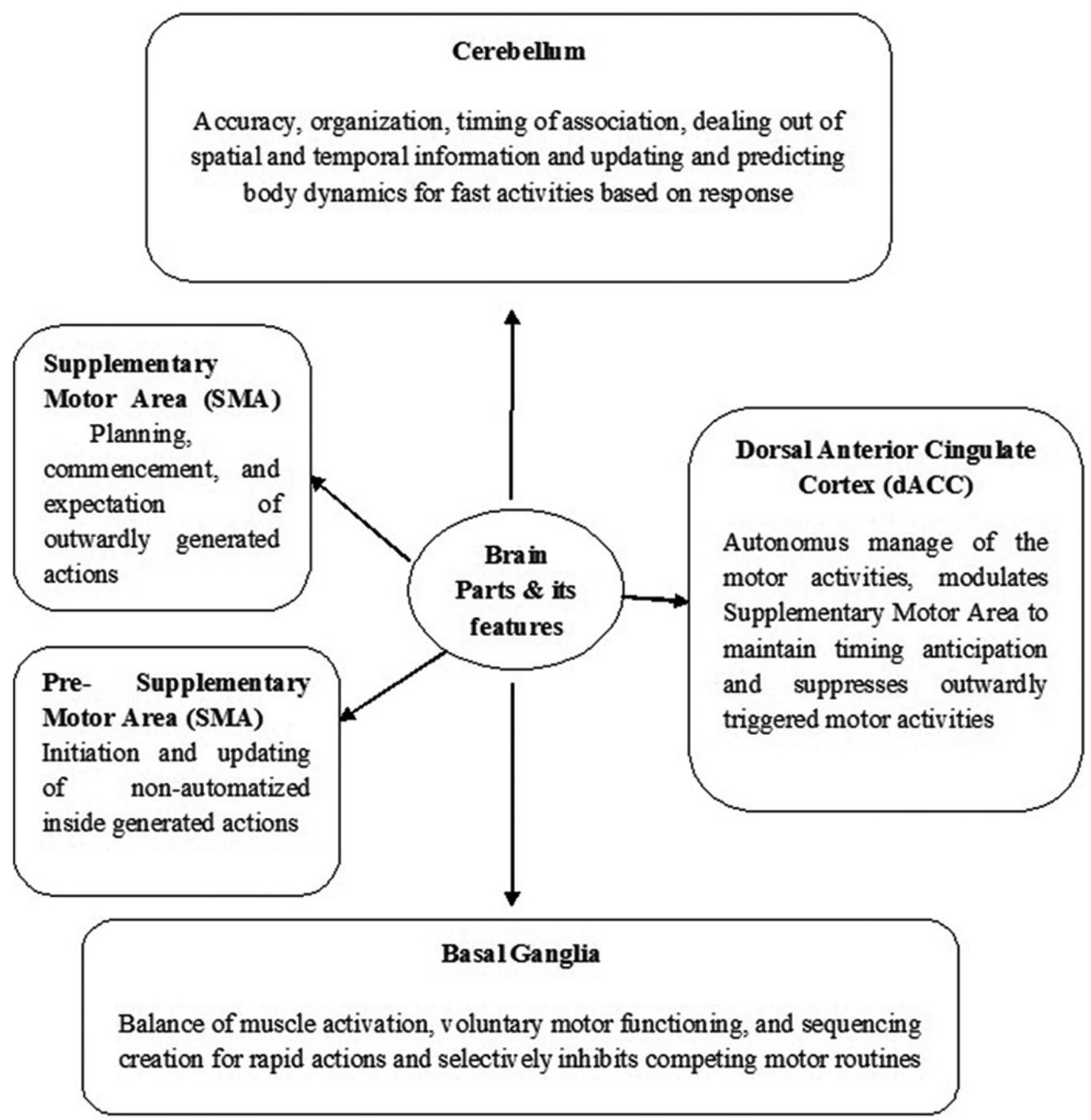

Fig. 3: Brain parts involved in schizophrenia 
Table 2: Schizophrenic symptoms produced by different brain parts abnormality

\begin{tabular}{|c|c|c|c|c|}
\hline S.No. & Brain part & Abnormality & Schizophrenic symptom & Reference \\
\hline 1. & $\begin{array}{l}\text { mOFC and rostral part of the anterior cingulate } \\
\text { cortex (rACC) }\end{array}$ & $\begin{array}{l}\text { White matter abnormalities within } \\
\text { connections between mOFC and rACC } \\
\text { (reductions in fractional anisotropy) }\end{array}$ & $\begin{array}{l}\text { Anhedonia-asociality and } \\
\text { avolition-apathy }\end{array}$ & {$[90]$} \\
\hline 2. & Left superior and middle temporal gyri & Gray matter reductions & Auditory hallucinations & [91] \\
\hline 3 & Ventricles and the basal nuclei & Larger than normal & $\begin{array}{l}\text { Controlling and planning } \\
\text { movements and cognition }\end{array}$ & [92] \\
\hline 4 & Hippocampus and amygdale & Bilateral volume reduction & $\begin{array}{l}\text { Thought disorder and } \\
\text { negative symptoms }\end{array}$ & [93] \\
\hline 5 & Thalamus & Volume reduction & $\begin{array}{l}\text { Execution of function and } \\
\text { sensory integration }\end{array}$ & {$[94]$} \\
\hline 6 & Pre-frontal cortex & $\begin{array}{l}\text { Altered functional connectivity, } \\
\text { decreased gray matter (lower activation } \\
\text { in response to goal-representation } \\
\text { demands) }\end{array}$ & $\begin{array}{l}\text { Suicidal behavior and } \\
\text { impairment of executive } \\
\text { functioning }\end{array}$ & [95-97] \\
\hline 7 & Dorsolateral prefrontal cortex & $\begin{array}{l}\text { Reduced GABA synthesis and disruption } \\
\text { of the glycosylation process }\end{array}$ & $\begin{array}{l}\text { Working memory } \\
\text { dysfunction }\end{array}$ & {$[20]$} \\
\hline 9 & Basal ganglia & $\begin{array}{l}\text { Abnormal morphology of the striatum } \\
\text { and globus pallidus }\end{array}$ & $\begin{array}{l}\text { Motor function and higher } \\
\text { level cognitive decision of } \\
\text { voluntary movements are } \\
\text { influenced }\end{array}$ & {$[100]$} \\
\hline 10 & SMA (supplementary motor cortex) & $\begin{array}{l}\text { Abnormal gray matter volume and } \\
\text { decreased cortical thickness }\end{array}$ & $\begin{array}{l}\text { Role in the externally } \\
\text { generated movements }\end{array}$ & [101-103] \\
\hline 11 & $\begin{array}{l}\text { dACC (dorsal anterior cingulated/ } \\
\text { midcingulated cortex }\end{array}$ & $\begin{array}{l}\text { Reduction in gray matter volume and } \\
\text { interneuron }\end{array}$ & $\begin{array}{l}\text { Functional connections to } \\
\text { the lateral prefrontal cortex, } \\
\text { limbic structure, striatum, } \\
\text { SMA }\end{array}$ & {$[102-104]$} \\
\hline
\end{tabular}

mOFC: Medial orbitofrontal cortex, rACC: Rostral part of the anterior cingulate cortex, GABA: Gamma-aminobutyric acid, dACC: Dorsal anterior cingulate cortex

Wide range of neurotransmitters' receptors (biogenic amines, amino acids, and neuropeptides) exists in the hippocampus, as well as other medial temporal cortical regions.

The prefrontal cortex is an area that is known to be concerned with executive functioning and it is well-known fact that these functions are impaired in SCZ [85]. Many studies also suggest the hyperactivity of hippocampus in SCZ [86]. The hippocampal formation is site of memory and learning. It has a major role in the medial temporaldiencephalic-basal forebrain system that mediates the compilation of short-term memory into long-term memory, thus it enables the attainment and preservation of novel information [87]. Schizophrenic patients show abnormal learning and memory performance related to verbal and visual material which is similar to temporal lobe epilepsy. SCZ is associated with hippocampal volume reduction, most of the neuroimaging studies had failed to express an association between long-term memory and hippocampal or temporal lobe volume reduction in schizophrenic patients indicating that non-hippocampal brain regions (e.g., cerebellum, thalamus, prefrontal, and parietal association cortex) play a major role in the cognitive deficits that characterize schizophrenia $[88,89]$. Schizophrenic symptoms produced by different brain parts abnormality are discussed in Table 2 .

\section{CONCLUSION}

SCZ is a chronic heterogeneous syndrome of disorganized and bizarre thoughts, delusions, hallucinations, inappropriate affect, and impaired psychosocial functioning. SCZ is likely a neurodevelopment disorder that may also think to be affected by ongoing changes in the brain structure. The tools of modern neuroscience, drawing from neuroanatomy, neurophysiology, brain imaging, and psychopharmacology, promise to provide a host of new insights into the etiology and treatment of SCZ. The pathophysiology of brain regions known to be involved in motor function may help in understanding the disturbed cognitive functions in SCZ, given that thinking may be an active motor process. Nevertheless, a cure or at least better treatments are sorely needed, and a greater understanding of the neurobiology of SCZ is crucial to both destigmatizing the illness and advancing clinical care.

\section{REFERENCES}

1. Andreasen NC. Symptoms, signs, and diagnosis of schizophrenia. Lancet 1995;346:477-81

2. Jablensky A, Sartorius N, Ernberg G, Anker M, Korten A, Cooper JE, et al. Schizophrenia: Manifestations, incidence and course in different cultures. A World health organization ten-country study. Psychol Med Monogr Suppl 1992;20:1-97.

3. Ross CA, Margolis RL, Reading SA, Pletnikov M, Coyle JT. Neurobiology of schizophrenia. Neuron 2006;52:139-53.

4. Singh SM, O'Reilly R. (Epi) genomics and neurodevelopment in schizophrenia: Monozygotic twins discordant for schizophrenia augment the search for diseaserelated (epi) genomic alterations. Genome Natl Res Council Canada 2009;52:8-19.

5. Jaaro-Peled H, Hayashi-Takagi A, Seshadri S, Kamiya A, Brandon NJ, Sawa A, et al. Neurodevelopmental mechanisms of schizophrenia: Understanding disturbed postnatal brain maturation through neuregulin1-erbB4 and DISC1. Trends Neurosci 2009;32:485-95.

6. Hayashi-Takagi A, Sawa A. Disturbed synaptic connectivity in schizophrenia: Convergence of genetic risk factors during neurodevelopment. Brain Res Bull 2010;83:140-6.

7. Keshavan MS, Tandon R, Boutros NN, Nasrallah HA. Schizophrenia "just the facts": What we know in 2008 Part 3: Neurobiology. Schizophr Res 2008;106:89-107.

8. Rice DP. The economic impact of schizophrenia. J Clin Psychiatry 1999;60 Suppl 1:4-6.

9. Andreasen NC. Schizophrenia: The fundamental questions. Brain Res Brain Res Rev 2000;31:106-12.

10. Erlenmeyer-Kimling L, Rock D, Roberts SA, Janal M, Kestenbaum C, Cornblatt B, et al. Attention, memory, and motor skills as childhood 
predictors of schizophrenia-related psychoses: The new york high-risk project. Am J Psychiatry 2000;157:1416-22.

11. Vishnupriya R, Ezhilramya B, Meenakshi B. Metformin in the prevention of metabolic syndrome associated with initiation of atypical antipsychotic therapy in adolescents and young adults-a randomized, open labelled, single centered study. Int J Pharm Pharm Sci 2016;8:200-6

12. Leonard BE. Fundamentals of Psychopharmacology. $3^{\text {rd }}$ ed. New York: John Wiley and Sons, Ltd.; 2003. p. 1-445.

13. Parle MA. Anti-psychotic activity of Pyrus communis Juice. Int $\mathrm{J}$ Pharm Pharm Sci 2017;9:113-20.

14. Weickert TW, Goldberg TE, Gold JM, Bigelow LB, Egan MF, Weinberger DR, et al. Cognitive impairments in patients with schizophrenia displaying preserved and compromised intellect. Arch Gen Psychiatry 2000;57:907-13.

15. Ohnuma T, Arai H. Pathophysiology of patients with schizophrenia: Genetic and Environmental factors. Juntendo Med J 2017;63:8-16.

16. Lieberman JA, Perkins D, Belger A, Chakos M, Jarskog F, Boteva K, et al. The early stages of schizophrenia: Speculations on pathogenesis, pathophysiology, and therapeutic approaches. Biol Psychiatry 2001;50:884-97.

17. Glatt SJ, Jönsson EG. The cys allele of the DRD2 ser311Cys polymorphism has a dominant effect on risk for schizophrenia: Evidence from fixed-and random-effects meta-analyses. Am J Med Genet B Neuropsychiatr Genet 2006;141B:149-54.

18. Toth M, Tecott L. Transgenic approach to epilepsy. Adv Neurol 1999;79:291-6.

19. Willins DL, Berry SA, Alsayegh L, Backstrom JR, Sanders-Bush E, Friedman L, et al. Clozapine and other 5-hydroxytryptamine-2A receptor antagonists alter the subcellular distribution of 5-hydroxytryptamine2A receptors in vitro and in vivo. Neuroscience 1999;91:599-606.

20. Clinton SM, Meador-Woodruff JH. Abnormalities of the NMDA receptor and associated intracellular molecules in the thalamus in schizophrenia and bipolar disorder. Neuropsychopharmacology 2004:29:1353-62.

21. Pilowsky LS, Bressan RA, Stone JM, Erlandsson K, Mulligan RS, Krystal JH, et al. First in vivo evidence of an NMDA receptor deficit in medication-free schizophrenic patients. Mol Psychiatry 2006;11:118-9.

22. Benes FM. Emerging principles of altered neural circuitry in schizophrenia. Brain Res Brain Res Rev 2000;31:251-69.

23. Lin CH, Lane HY, Tsai GE. Glutamate signaling in the pathophysiology and therapy of schizophrenia. Pharmacol Biochem Behav 2012;100:665-77.

24. Grace AA. Dopamine system dysregulation by the hippocampus: Implications for the pathophysiology and treatment of schizophrenia. Neuropharmacology 2012;62:1342-8

25. Toda M, Abi-Dargham A. Dopamine hypothesis of schizophrenia: Making sense of it all. Curr Psychiatry Rep 2007;9:329-36.

26. Lewis DA, Hashimoto T, Volk DW. Cortical inhibitory neurons and schizophrenia. Nat Rev Neurosci 2005;6:312-24.

27. Moghaddam B. Bringing order to the glutamate chaos in schizophrenia. Neuron 2003;40:881-4

28. Fallon JH, Opole IO, Potkin SG. The neuroanatomy of schizophrenia: Circuitry and neurotransmitter systems. Clin Neurosci Res 2003;3:77-107.

29. Perez-Costas E, Melendez-Ferro M, Roberts RC. Basal ganglia pathology in schizophrenia: Dopamine connections and anomalies. J Neurochem 2010;113:287-302.

30. Howes OD, Kapur S. The dopamine hypothesis of schizophrenia: Version III-the final common pathway. Schizophr Bull 2009;35:549-62.

31. Cazorla M, de Carvalho FD, Chohan MO, Shegda M, Chuhma N, Rayport S, et al. Dopamine D2 receptors regulate the anatomical and functional balance of basal ganglia circuitry. Neuron 2014;81:153-64.

32. Seeman P, Seeman MV. Schizophrenia and the supersensitive synapse. Neuropsychiatry 2011;1:233-42.

33. Brittain JS, Brown P. Oscillations and the basal ganglia: Motor control and beyond. Neuroimage 2014;85 Pt 2:637-47.

34. Harrington D, Hening W, Poizner H. Basal Ganglia: Motor Functions. New Jersey: University of Medicine and Dentistry of New Jersey; 2009. p. 346-50.

35. Vollenweider FX, Vontobel P, Oye I, Hell D, Leenders KL. Effects of S-ketamine on striatal dopamine: A [11C]-raclopride PET study of a model psychosis in humans. J Psychiatr Res 2000;34:35-43.

36. Huang EJ, Reichardt LF. Neurotrophins: Roles in neuronal development and function. Annu Rev Neurosci 2001;24:677-736.

37. Spenger C, Hyman C, Studer L, Egli M, Evtouchenko L, Jackson C, et al. Effects of BDNF on dopaminergic, serotonergic, and GABAergic neurons in cultures of human fetal ventral mesencephalon. Exp Neurol 1995; 133:50-63

38. Xiu MH, Hui L, Dang YF, Hou TD, Zhang CX, Zheng YL, et al. Decreased serum BDNF levels in chronic institutionalized schizophrenia on long-term treatment with typical and atypical antipsychotics. Prog Neuropsychopharmacol Biol Psychiatry 2009;33:1508-12.

39. Laruelle M. The role of endogenous sensitization in the pathophysiology of schizophrenia: Implications from recent brain imaging studies. Brain Res Brain Res Rev 2000;31:371-84.

40. Burnet PW, Eastwood SL. Harrison PJ 5-HT1A and 5-HT2A receptor mRNAs and binding site densities are differentially altered in schizophrenia. Neuropsychopharmacology 1996;15:442-55.

41. Raymond JR, Mukhin YV, Gelasco A, Turner J, Collinsworth G, Gettys TW, et al. Multiplicity of mechanisms of serotonin receptor signal transduction. Pharmacol Ther 2001;92:179-212.

42. Harrison PJ. Neurochemical alterations in schizophrenia affecting the putative receptor targets of atypical antipsychotics. Focus on dopamine (D1, D3, D4) and 5-HT2a receptors. Br J Psychiatry Suppl 1999;38:12-22.

43. Lodge D. The history of the pharmacology and cloning of ionotropic glutamate receptors and the development of idiosyncratic nomenclature. Neuropharmacology 2009;56:6-21

44. Kalia LV, Kalia SK, Salter MW. NMDA receptors in clinical neurology: Excitatory times ahead. Lancet Neurol 2008:7:742-55.

45. Labrie V, Roder JC. The involvement of the NMDA receptor D-serine/ glycine site in the pathophysiology and treatment of schizophrenia. Neurosci Biobehav Rev 2010;34:351-72

46. Matsuzaki M, Honkura N, Ellis-Davies GC, Kasai H. Structural basis of long-term potentiation in single dendritic spines. Nature 2004:429:761-6.

47. Quinlan EM, Olstein DH, Bear MF. Bidirectional, experience-dependent regulation of Nmethyl-D-aspartate receptor subunit composition in the rat visual cortex during postnatal development. Proc Natl Acad Sci USA 1999;96:12876-80.

48. Yashiro K, Philpot BD. Regulation of NMDA receptor subunit expression and its implications for LTD, LTP, and metaplasticity. Neuropharmacology 2008;55:1081-94

49. van Zundert B, Yoshii A, Constantine-Paton M. Receptor compartmentalization and trafficking at glutamate synapses: A developmental proposal. Trends Neurosci 2004;27:428-37.

50. Javitt DC. Glycine transport inhibitors and the treatment of schizophrenia. Biol Psychiatry 2008;63:6-8.

51. McDonald JW, Johnston MV. Physiological and pathophysiological roles of excitatory amino acids during central nervous system development. Brain Res Brain Res Rev 1990;15:41-70.

52. Carlsson A, Waters, N, Waters S, Carlsson ML. Network interactions in schizophrenia: Therapeutic implications. Brain Res Brain Res Rev 2000;31:342-9.

53. Jentsch JD, Roth RH. The neuropsychopharmacology of phencyclidine: From NMDA receptor hypofunction to the dopamine hypothesis of schizophrenia. Neuropsychopharmacology 1999;20:201-25.

54. Coyle JT. The glutamatergic dysfunction hypothesis for schizophrenia. Harv Rev Psychiatry 1996;3:241-53

55. Ayano G. Dopamine: Receptors, functions, synthesis, pathways, locations and mental disorders: Review of literatures. J Ment Disord Treat 2016;2:120.

56. Goto Y, Yang CR, Otani S. Functional and dysfunctional synaptic plasticity in prefrontal cortex: Roles in psychiatric disorders. Biol Psychiatry 2010;67:199-207.

57. Lisman J, Grace AA, Duzel E. A neoHebbian framework for episodic memory; Role of dopamine-dependent late LTP. Trends Neurosci 2011;34:536-47.

58. Kegeles LS, Abi-Dargham A, Zea-Ponce Y, Rodenhiser-Hill J, Mann JJ, Van Heertum RL, et al. Modulation of amphetamine-induced striatal dopamine release by ketamine in humans: Implications for schizophrenia. Biol Psychiatry 2000;48:627-40.

59. Wobrock T, Kadovic D, Falkai P. Cortical excitability in schizophrenia. Studies using transcranial magnetic stimulation. Nervenarzt 2007;78:753-4, 756-63.

60. Perry E, Walker M, Grace J, Perry R. Acetylcholine in mind: A neurotransmitter correlate of consciousness? Trends Neurosci 1999;22:273-80

61. Dean B. Evolution of the human CNS cholineric system: Has this resulted in the emergence of psychiatric disease? Aust N Z J Psychiatry 2009;43:1016-28.

62. Thiele A. Muscarinic signaling in the brain. Annu Rev Neurosci 
2013;36:271-94

63. Dean B, Crook JM, Opeskin K, Hill C, Keks N, Copolov DL, et al. The density of muscarinic M1 receptors is decreased in the caudateputamen of subjects with schizophrenia. Mol Psychiatry 1996;1:54-8.

64. Scarr E, Sundram S, Keriakous D, Dean B. Altered hippocampal muscarinic M4, but not M1, receptor expression from subjects with schizophrenia. Biol Psychiatry 2007;61:1161-70.

65. Mancama D, Arranz MJ, Landau S, Kerwin R. Reduced expression of the muscarinic 1 receptor cortical subtype in schizophrenia. Am J Med Genet B Neuropsychiatr Genet 2003;119B:2-6.

66. Beck AT, Reactor NA, Stolar N, Grant P. Biological Contribution in Schizophrenia: Cognitive Theory, Research and Therapy. New York: Guilford Press; 2009. p. 30-61.

67. Schwartz JH, Javitch JA. Neurotransmitter: Principles of Neural Science. $5^{\text {th }}$ ed. New York: McGraw Hill; 2013. p. 28-305.

68. Izawa J, Asai T, Imamizu H. Computational motor control as a window to schizophrenia. Neurosci Res 2016;104:44-51.

69. Woodcock EA, Wadehra S, Diwadkar VA. Network profiles of the dorsal anterior cingulate and dorsal prefrontal cortex in schizophrenia during hippocampal-based associative memory. Front Syst Neurosci 2016;10:32

70. Witt ST, Laird AR, Meyerand ME. Functional neuroimaging correlates of finger-tapping task variations: An ALE meta-analysis. Neuroimage 2008;42:343-56.

71. Davis KL, Kahn RS, Ko G, Davidson M. Dopamine in schizophrenia: A review and reconceptualization. Am J Psychiatry 1991;148:1474-86.

72. Bogerts B. Recent advances in the neuropathology of schizophrenia. Schizophr Bull 1993;19:431-45.

73. Shenton ME, Kikinis R, Jolesz FA, Pollak SD, LeMay M, Wible CG, et al. Abnormalities of the left temporal lobe and thought disorder in schizophrenia. A quantitative magnetic resonance imaging study. N Engl J Med 1992;327:604-12.

74. Vita A, Bressi S, Perani D, Invernizzi G, Giobbio GM, Dieci M, et al. High-resolution SPECT study of regional cerebral blood flow in drug-free and drug-naive schizophrenic patients. Am J Psychiatry $1995 ; 152: 876-82$.

75. Zaidel DW, Esiri MM, Harrison PJ. The hippocampus in schizophrenia: Lateralized increase in neuronal denstiy and altered cytoarchitectural asymmetry. Psychol Med 1997;27:703-13.

76. Middleton FA, Strick PL. Basal gangilia and cerebellar loops: Motor and cognitive circuits. Brain Res Brain Res Rev 2000;31:236-50.

77. Bombin I, Arango C, Buchanan RW. Significance and meaning of neurological signs in schizophrenia: Two decades later. Schizophr Bull 2005;31:962-77.

78. Yang $\mathrm{H}$, He $\mathrm{H}$, Zhong $\mathrm{J}$, Multimodal MR. Characterisation of schizophrenia: 851 A discriminative analysis. Lancet 2016;388:S36.

79. Friston K, Brown HR, Siemerkus J, Stephan KE. The dysconnection hypothesis 595 (2016). Schizophr Res 2016;176:83-94.

80. Patel N, Jankovic J, Hallett M. Sensory aspects of movement disorders. Lancet Neurol 2014;13:100-12.

81. Picazio S, Koch G. Is motor inhibition mediated by cerebello-cortical interactions? Cerebellum 2015;14:47-9.

82. Salman MS, Tsai P. The role of the pediatric cerebellum in motor functions, cognition, and behavior: A Clinical perspective. Neuroimaging Clin N Am 2016;26:317-29.

83. Ivry RB, Spencer RM. The neural representation of time. Curr Opin Neurobiol 2004;14:225-32

84. Graybiel AM. The basal ganglia. Trends Neurosci 1995;18:60-2

85. Weinberger DR, Gallhofer B. Cognitive function in schizophrenia. Int Clin Psychopharmacol 1997;12 Suppl 4:S29-36.

86. Heckers S. Neuroimaging studies of the hippocampus in schizophrenia.
Hippocampus 2001;11:520-8.

87. Squire LR, Zola-Morgan S. The medial temporal lobe memory system. Science 1991;253:1380-6.

88. Nelson MD, Saykin AJ, Flashman LA, Riordan HJ. Hippocampal volume reduction in schizophrenia as assessed by magnetic resonance imaging: A meta-analytic study. Arch Gen Psychiatry 1998;55:433-40.

89. Torres IJ, Flashman LA, O'Leary DS, Swayze V $2^{\text {nd }}$, Andreasen NC. Lack of an association between delayed memory and hippocampal and temporal lobe size in patients with schizophrenia and healthy controls. Biol Psychiatry 1997;42:1087-96.

90. Ohtani T, Bouix S, Hosokawa T, Saito Y, Eckbo R, Ballinger T, et al. Abnormalities in white matter connections between orbitofrontal cortex and anterior cingulate cortex and their associations with negative symptoms in schizophrenia: A DTI study. Schizophr Res 2014;157:190-7.

91. García-Martí G, Aguilar EJ, Martí-Bonmatí L, Escartí MJ, Sanjuán J. Multimodal morphometry and functional magnetic resonance imaging in schizophrenia and auditory hallucinations. World J Radiol 2012;4:159-66.

92. Haukvik UK, Hartberg CB, Agartz I. Schizophrenia-what does structural MRI show? Tidsskr Nor Laegeforen 2013;133:850-3

93. Rajarethinam R, DeQuardo JR, Miedler J, Arndt S, Kirba R, Brunberg JA, et al. Hippocampus and amygdala in schizophrenia: Assessment of the relationship of neuroanatomy to psychopathology. Psychiatry Res 2001;108:79-87.

94. Agarwal N, Rambaldelli G, Perlini C, Dusi N, Kitis O, Bellani M, et al. Microstructural thalamic changes in schizophrenia: A combined anatomic and diffusion weighted magnetic resonance imaging study. J Psychiatry Neurosci 2008;33:440-8.

95. Minzenberg MJ, Lesh TA, Niendam TA, Yoon JH, Rhoades RN, Carter CS, et al. Frontal cortex control dysfunction related to longterm suicide risk in recent-onset schizophrenia. Schizophr Res 2014;157:19-25.

96. Anticevic A, Hu X, Xiao Y, Hu J, Li F, Bi F, et al. Early-course unmedicated schizophrenia patients exhibit elevated prefrontal connectivity associated with longitudinal change. J Neurosci 2015;35:267-86.

97. Frascarelli M, Tognin S, Mirigliani A, Parente F, Buzzanca A, Torti MC, et al. Medial frontal gyrus alterations in schizophrenia: Relationship with duration of illness and executive dysfunction. Psychiatry Res 2015;231:103-10.

98. Pollok B, Butz M, Gross J, Südmeyer M, Timmermann L, Schnitzler A, et al. Coupling between cerebellar hemispheres: Behavioural, anatomic, and functional data. Cerebellum 2006;5:212-9.

99. Batson MA, Petridou N, Klomp DW, Frens MA, Neggers SF. Single session imaging of cerebellum at 7 tesla: Obtaining structure and function of multiple motor subsystems in individual subjects. PLoS One 2015;10:e134933.

100. Morris LS, Kundu P, Dowell N, Mechelmans DJ, Favre P, Irvine MA, et al. Fronto-striatal organization: Defining functional and microstructural substrates of behavioural flexibility. Cortex 2016;74:118-33.

101. Nachev P, Kennard C, Husain M. Functional role of the supplementary and pre-supplementary motor areas. Nat Rev Neurosci 2008;9:856-69.

102. Dum RP, Levinthal DJ, Strick PL. Motor, cognitive, and affective areas of the cerebral cortex influence the adrenal medulla. Proc Natl Acad Sci U S A 2016;113:9922-7.

103. Dum RP, Strick PL. Motor areas in the frontal lobe of the primate. Physiol Behav 2002;77:677-82.

104. Hutchison RM, Womelsdorf T, Gati JS, Leung LS, Menon RS, Everling S, et al. Resting-state connectivity identifies distinct functional networks in macaque cingulate cortex. Cereb Cortex 2012;22:1294-308. 